\title{
(DES)ESTABILIDADES DO REGIME CISCOLONIALISTA A PARTIR DO CASO DA ESTUDANTE/ATLETA MARIANA CARVALHO DOS SANTOS
}

\author{
Rafael Marques Garcia ${ }^{1}$ \\ Eduarda Assunção Niemeyer Leite ${ }^{2}$ \\ Erik Giuseppe Barbosa Pereira $^{3}$
}

Resumo: Desenvolvemos um estudo de caso com a estudante/atleta Mariana Carvalho dos Santos, uma mulher transexual negra, de classe social baixa e periférica, graduanda em Educação Física pela Universidade Federal do Rio de Janeiro. Problematizamos o regime ciscolonialista que rege as instâncias sociais às quais Mariana transita, com destaque à Universidade e ao Esporte nas modalidades judô e voleibol. Nossos apontamentos indicam resistências à Mariana, que sofre processos transfóbicos ciscolonialistas, com a não passabilidade de gênero, com o não reconhecimento de sua identificação, com os trâmites burocráticos do Estado, da Universidade e das práticas esportivas, bem como das resistências para poder atuar no mercado formal da Educação Física.

Palavras-chave: Colonialismo; Cisnormatividade; Normas de gênero; Esportes; Educação Física.

\section{(Dises)stabilities in the Ciscolonialist Regime through the case of the student/athlete Mariana Carvalho dos Santos}

\begin{abstract}
We developed a case study with the student/athlete Mariana Carvalho dos Santos, a black transsexual woman, of low and peripheral social class, graduating in Physical Education at the Federal University of Rio de Janeiro. We problematize the ciscolonial regime that governs the social instances that Mariana transits, with emphasis on the University and Sports in the judo and volleyball modalities. Our notes indicate resistance to Mariana, who suffers from ciscolonialist transphobic processes, with no gender passability, with no recognition of her identification, with the bureaucratic procedures of the State, the University and sports practices, as well as resistance to be able to work in the formal Physical Education market.
\end{abstract}

Keywords: Colonialism; Cisnormativity; Gender norms; Sports; Physical Education.

\footnotetext{
'Universidade Federal do Rio de Janeiro (rafa.mgarcia@ hotmail.com)

${ }^{2}$ Universidade Federal do Rio de Janeiro (dudart.niemeyer@yahoo.com.br)

${ }^{3}$ Universidade Federal do Rio de Janeiro (egiueppe@ eefd.ufrj.br)
} 


\section{INTRODUÇÃO}

$\mathrm{Na}$ contemporaneidade, as identificações sociais multiplicaram-se em incontáveis marcadores de diferenças ${ }^{4}$ que abrangem características sobre sexo, gênero, sexualidade, orientação sexual, raça, etnia, geração, religião, classe social, deficiência e outros aspectos que moldam a personalização humana nas sociedades atuais. Em meio a essas disputas de redes de poder, Vergueiro (2015) identifica aquele regime que, historicamente, se sobrepôs a todos os outros e encontra-se estabelecido nos países ocidentais: o ciscolonialismo.

O ciscolonialismo traduz-se em uma política de imposição do poder à luz de normatividades que se expandem aos grupos que, na interpretação dos detentores de poder, precisam ser educados à luz desse cistema. Neste cenário, retomamos ao processo de colonialismo dos séculos XV e XVI, onde os homens brancos, europeus, cristãos, heterossexuais, patriarcais, de classe média/alta, letrados, sem deficiências físicas e intelectuais dominaram territórios continentais, levando sua filosofia de vida extirpadora às terras e aos seus nativos que ali habitavam. Processos escravocratas, mandatários e de grandeza se formaram à luz e semelhança desse ser humano colonizador, onde todo aspecto que desvie ou fuja desta imagem é, portanto, inferior, subalterno e insignificante, devendo, portanto, ser corrigido ou, caso seja impossível fazê-lo, deve ser tratado como pária social (VERGUEIRO, 2015).

Em adição, Paul Preciado, filósofo e escritor feminista transgênero explica que, socialmente, as identificações que adotamos ao longo de nosso percurso de vida fazem parte de redes de relações de poder que moldam os corpos a partir de marcadores. Neste sentido, o autor sinaliza a existência de tecnologias de poder que se instituem sobre os corpos a partir de uma arquitetura política e jurídica que herdamos do colonialismo patriarcal, que fixa as diferenças inatas entre os sexos, estabelece hierarquias raciais, valoriza determinas estruturas familiares e destina ao Estado o poder de direcionar os parâmetros que possam

\footnotetext{
${ }^{4}$ A noção de diferença, conforme explica Brah (2006), pode ser conceituada de quatro maneiras: diferença como experiência, diferença como relação social, diferença como subjetividade e diferença como identidade. Neste texto, vamos nos ater ao segundo produto, que a autora define como a "[...] maneira como a diferença é constituída e organizada em relações sistemáticas através de discursos econômicos, culturais e políticos e práticas institucionais. Isso quer dizer que destaca a sistematicidade através das contingências. Um grupo geralmente mobiliza o conceito de diferença neste sentido quando trata das genealogias históricas de sua experiência coletiva" (BRAH, 2006, p. 362).
} 
ser considerados normais em termos jurídicos de reconhecimento sociocultural (PRECIADO, 2019).

Neste sentido, Vergueiro (2015) sinaliza como somos todos marcados por modelos que, embora sejam diversificados, são unificados para atender aos desmandos normatizadores da cisnormatividade colonial. Desta forma, as singularidades pessoais seriam pouco a pouco minadas, contribuindo para a criação e manutenção de grupamentos sociais normalizados, isto é, adestrados à luz das cisnormas.

Estas diversidades, a partir da percepção de que suas corpas e perspectivas de gênero são inferiorizadas e desumanizadas em relação às normatividades cisgêneras, teriam nela o interesse comum que definiria essa comunidade colonizada: tomar consciência da vigência de um cistema colonial de gênero consistiria, assim, em enxergar criticamente a hierarquização cistêmica e interseccional das perspectivas cisgêneras acima das diversidades corporais e de identidades de gênero, e em encontrar formas de resistência existenciais, socioculturais e políticas contra este regime de violências (VERGUEIRO, 2015, p. 42).

A cisnormatividade, conforme sinaliza Vergueiro (2015, p. 43), pode ser compreendida como "uma normatividade de gênero [...] que exerce, através de variados dispositivos de poder interseccionalmente situados, efeitos colonizatórios sobre corpos, existências, vivências, identidades e identificações de gênero". A autora complementa: "[...] podemos tomar a cisnormatividade como uma série de forças socioculturais e institucionais que discursivamente produzem a cisgeneridade como 'natural'" (p. 68), adotando para si preceitos heteronormativos, cissexuais e cisgêneros: "[...] escolho utilizar os termos cisnormatividade e cissexismo, sendo este último termo, em particular, utilizado com o propósito de enfatizar caminhos interseccionais com o conceito de sexismo" (p. 69).

Para Vergueiro (2015, p. 15), a cisgeneridade e a cissexualidade fazem parte do que a autora denomina de Cistema-mundo, em alusão ao trabalho Descolonizar as esquerdas ocidentalizadas: para além das esquerdas eurocêntrica rumo a uma esquerda transmoderna descolonial do sociólogo porto-riquenho Ramón Grosfoguel. Assim, constrói a genealogia da cisgeneridade e seus correlatos, caracterizando o Cistema-mundo como

[...] "ocidentalizado/cristianocêntrico moderno/colonial capitalista/ patriarcal" que produz "hierarquias epistêmicas" em que [...] 
perspectivas não cisgêneras são excluídas, minimizadas, ou silenciadas. A corruptela "cistema”, entre outras corruptelas do tipo, têm o objetivo de enfatizar o caráter estrutural e institucional - "cistêmico" - de perspectivas cis+sexistas, para além do paradigma individualizante do conceito de "transfobia" (VERGUEIRO, 2015, p. 15).

Neste cenário, as transgeneridades, que abarcam as identificações transexuais, travestis e também aquelas que não adotam posição fixa do sexo/gênero, ao se deflagrarem enquanto identificações críticas pelos espaços sociais, perturbam o ciscolonialismo embutido nas estruturas que operam nossa civilidade, tornando-se, portanto, potencialmente problematizadores ao próprio discurso da normalização cistêmica (VERGUEIRO, 2015).

Para Preciado, a identificação e mudanças corporais promovidas pela transgeneridade traduz-se em um ato de dissidência sociopolítica que ultrapassa a lógica identitária e deflagra a crise do paradigma científico da diferença entre os sexos. Desta forma, o autor problematiza a visão reducionista instituída aos corpos enquanto objetos anatômicos, um legado biomédico que se propaga desde o século XVI instituindo representações normativas sobre os corpos. Preciado destaca que o corpo é um instrumento biopolítico de vida que se fabrica não apenas do patriarcado ou da biomedicina, mas também pelas artes, pelos recursos audiovisuais, pelo regime mercadológico, pelas instâncias sociais, etc. A identificação e reconhecimento do corpo se faz a partir de seus próprios marcadores, tais como o sexo, o gênero, a sexualidade, a raça, a condição de saúde, a deficiência, o pensamento, a religião, enfim, em todas as categorias que se multiplicam em contestações que estremecem as tecnologias do poder e assim os estabelecem (PRECIADO, 2019), explicitando em termos práticos as peculiaridades de identidade e experiência na construção das diferenças (BRAH, 2006).

Cientes dessa estrutura ciscolonialista, que inferioriza pessoas de raça não ariana, as mulheres, pessoas com deficiência, pessoas trans, gays, lésbicas, bissexuais, analfabetos, de classe baixa, despolitizados, ateus e/ou praticantes de outras religiões que não a judaico-cristã, enfim, toda e qualquer ordem que não seja aquela do ser humano ciscolonizador, trazemos aqui o relato de Mariana Carvalho dos Santos, uma mulher transexual negra, residente no bairro de Anchieta, zona norte da cidade do Rio de Janeiro, para problematizar os desdobramentos de sua identificação transexual na Educação Física e no Esporte. 
Mariana é estudante de Educação Física da Universidade Federal do Rio de Janeiro (UFRJ), tendo iniciado seus estudos na referida instituição no primeiro semestre de 2014. Neste período, ainda se reconhecia como um homem homossexual. Ao longo de seu percurso acadêmico, começou a sua transição de gênero no ano de 2015, trazendo à tona a discussão sobre a transexualidade e/na Educação Física no meio acadêmico, já que ela foi a primeira aluna da Escola de Educação Física e Desportos (EEFD) a ter sua identificação social reconhecida pela Universidade através, inclusive, da mudança de seu nome nos documentos acadêmicos, que foi solicitado e deferido via plataforma digital de acesso da UFRJ.

Talvez incorra ao/à leitor/a a seguinte pergunta: mas qual a relação entre esses aspectos ciscolonialistas e a Educação Física e/ou Esporte? Silvana Goellner (2008) explica que o Esporte, no contexto brasileiro do século XX, tal qual as instituições normativas das sociedades modernas, se estruturou a partir de relações entre raça, gênero, eugenia e nacionalismo. Traduziu-se em um movimento político-científico que visava a formação de uma sociedade forte, saudável e soberana, assentadas fortemente na exacerbação da prática de atividades físicas em prol da saúde. Contudo, o interesse maior foi pela constituição de uma raça branca forte que herdasse as virtudes de seus antepassados à luz de um ideal imaginário de uma população que temesse a mestiçagem. Nesse sentido, a autora destaca o caráter onipresente das instâncias racistas que se imperavam nas práticas esportivas com o intuito de aprimorar corpos brancos. Neste sentido,

a noção de raça é uma categoria discursiva que historicamente tem operado cultural, política e simbolicamente em favor dos brancos, que deveriam ser cada vez mais aprimorados quanto às suas capacidades físicas e morais de forma a diferenciarem-se dos negros escravos ou descentes destes (GOELLNER, 2008, p. 10).

À luz da leitura histórica de Goellner (2008), percebemos que o contexto esportivo da atual sociedade brasileira se assenta em aspectos cistêmicos de séculos anteriores que foram incorporados à essa instituição com o intuito de construir uma raça elevada, ao mesmo ponto que almejava barrar e/ou impedir a ascendência dos considerados inferiores (isto é, os que desviam da cisnormatividade e/ou que se constituem pela própria noção de diferença).

Não obstante, aspectos político-econômicos também se embutem na instituição esportiva com o intuito de subordinar a população negra, por exemplo, 
da conquista de acesso e permanências nesses espaços. Djamila Ribeiro (2017) sinaliza que as questões de raça no Esporte funcionam como atributos de modalidades, onde os marcadores também se expõem para a inserção e atuação de atletas em algumas modalidades. Da mesma forma que se convencionou um entendimento de que existam modalidades masculinas e femininas, também se estruturou uma ideia de que existem as modalidades para brancos e outras para negros: "A ideia do negro incapaz intelectualmente permanece quando o único lugar possível é sendo esportista e, mesmo assim, em modalidades não elitistas” (RIBEIRO, 2017, p. 11).

Neste sentido, trazer o depoimento acadêmico-esportivo da estudante/atleta Mariana, uma mulher transexual, negra, periférica e de classe social baixa é importante para percebermos como os marcadores sociais da diferença interferem e/ou possibilitam na/a inserção/permanência/atuação em esferas sociais moldadas por termos ciscolonialistas, mais especificamente, a Universidade e o Esporte.

\section{O DEPOIMENTO DE MARIANA}

O presente trabalho, por tratar exclusivamente do caso da estudante/atleta Mariana, configura uma intervenção do tipo estudo de caso. Stake (1998) explica que para investigações deste cunho é primordial definir os contornos básicos do caso a ser investigado, apresentando seus dados mais representativos. Em suma, esta empreitada desenvolve uma análise crítico-descritiva que procura compreender e explorar um determinado fato (neste estudo, a inserção/atuação/permanência de Mariana pelas instâncias sociais às quais circula, mais especificamente a Universidade e o Esporte).

Mariana foi contatada em agosto de 2019 pelo pesquisador na EEFD/UFRJ. Foi-lhe concedido o convite para a participação na pesquisa mediante todos os termos éticos e legais para realização de pesquisas com seres humanos. Para tanto, previamente este estudo foi avaliado e aprovado pelo Comitê de Ética e Pesquisa do Hospital Universitário Clementino Fraga Filho da Universidade Federal do Rio de Janeiro - HUCFF/UFRJ -, sendo o no ${ }^{\circ}$ do Protocolo: 098-19; $\mathrm{n}^{\mathrm{o}}$ do CAAE: 10289419.5.0000.5257; e $\mathrm{n}^{\mathrm{o}}$ do parecer: 3.387.888.

A aluna recebeu o termo de consentimento livre e esclarecido (TCLE) para ciência e preenchimento, e concordou em conceder seu depoimento ao pesquisador. Na primeira data marcada para a entrevista, no mesmo mês do 
corrente ano, Mariana não pôde comparecer por problemas de saúde. A entrevista foi, então, remarcada para o mês de setembro de 2019. Desta vez, Mariana compareceu. A entrevista ocorreu nas dependências da EEFD/ UFRJ, na sala de reuniões da Coordenação de Pós-Graduação em Educação Física PPGEF.

De cunho biográfico-narrativa (STAKE, 1998), a entrevista foi uma espécie de bate-papo informal, onde buscamos conhecer o histórico de Mariana a partir de perguntas e o direcionamento ao qual nos foi possibilitado. A construção biográfica a partir da narrativa da estudante/atleta configurou a criação de uma história que posteriormente tornou-se nosso objeto de análise. Para tanto, aspectos socioculturais, temporais e contextuais foram problematizados ao longo desse momento.

Todo o depoimento de Mariana foi gravado através do aparelho celular Motorola $G-8$ pelo aplicativo Gravador de Voz. Posteriormente, em momento reservado, o pesquisador transcreveu as falas de forma literal e iniciou a escrita deste documento. Para facilitar a leitura e compreensão de nossos achados, organizamos os trechos por grupo de similaridades conforme as palavras puderam indicar termos de agrupamento, assim destrinchados: 1- Relações sociais e familiares; 2- A hormonização; 3- O tratamento na Universidade; 4- A participação nos Jogos Interperíodos; 5- Diferenças marcantes entre o voleibol e o judô; e 6- Perspectivas para o Esporte e vida profissional. Vale lembrar que, finalizada a redação deste documento, encaminhamo-lo à Mariana para que tomasse ciência de nossas interpretações e pudesse ratificá-las, retificá-las ou ainda, sugerir supressões. A versão que aqui disponibilizamos foi pré-aprovada pela depoente. Também, registre-se que, no momento da entrevista (ano de 2019) a mesma se reconhecia como mulher transexual, identificação não mais acionada no corrente ano de 2020 - Mariana agora se reconhece como travesti e abandonou as práticas esportivas, dedicando-se à frente de movimentos sociais e de resistências trans pela cidade do Rio de Janeiro/RJ.

\section{RELAÇÕES SOCIAIS E FAMILIARES}

Nesta seção, trazemos os trechos em que Mariana explica como se reconhecia socialmente e como essa identificação era interpretada pelos espaços sociais em que circulava. Essa discussão é importante pois, segundo Soares et al. (2011, p. 84), "A rede social pode oferecer diferentes tipos de apoio e os seus efeitos benéficos dependem da necessidade e da expectativa dos indivíduos”. 
Mariana (M) comentou:

M: Quando comecei judô, foi quando eu estava assexuada, então não tinha nada, sempre tinha um ou outro que sempre me chamou de viado durante todo esse processo do judô, só que eu era boa, mas isso passava, não era uma preocupação para as pessoas que treinavam comigo.

Ao ser questionada se em algum momento já havia sofrido algum tipo de preconceito em seus treinos, Mariana explicou uma situação que envolveu um de seus colegas:

M: O único menino que teve uma implicância muito grande comigo, ele achava que tinha alguma coisa que ele tinha que consertar, aí depois do treino ele sempre queria me jogar, eu tinha uns 14 anos, $58 \mathrm{~kg}$ mais ou menos, categoria que eu lutei na adolescência, e ele lutava numa categoria de $90 \mathrm{~kg}$ e ele já era adulto, e aí depois do treino ele tinha isso, até eles me machucarem, que foi ele e outro menino, me machucaram no sentido assim, ele me jogou aí o menino caiu em cima do meu joelho que eu estava treinando... não foi intencional, só aconteceu porque a gente estava ali aquele momento, foi a única pessoa que eu tive problema por conta da sexualidade, nessa época como eu já estava com 14-15 anos eu já sabia o que era... [homossexual].

Ao perguntarmos sobre sua família, Mariana demonstrou constrangimento e preferiu não se alongar nessa questão. Apenas disse:

M: Minha família é muito complicada, extremamente preconceituosa, nem tem o que falar sobre porque já se sabe o que espera de preconceituosos né.

Em pesquisa de Soares et al. (2011), os/as autores/as explicam que a identificação transexual pode ser classificada em dois grupos: a primária, onde a pessoa se reconhece nessa identificação desde a infância, renegando sua maturação biológica; e a secundária, onde esse processo ocorre mais tardiamente, na idade adulta. Mariana, sob esta ótica, pode ser considerada como uma transexual secundária, já que sua identificação ocorreu após alcançar a idade adulta.

Na adoção da nova identificação, Berenice Bento (2012) explica que, a partir deste momento, inicia-se o processo transexualizador, onde a pessoa passa a fazer uso de hormônios, passa a se vestir com roupas que são lidas como do 
gênero oposto, podem recorrer a cirurgias estéticas e/ou de transgenitalização e alterar o nome civil pelo nome social, por exemplo.

Este processo pode deflagrar certas reações nos núcleos sociais, principalmente a família da pessoa transexual. Bento (2012) expõe que, infelizmente, existem muito mais histórias de abandono e violências físicas e simbólicas cometidas a sujeitos transexuais no seio familiar do que casos em que há apoio, reconhecimento e defesa dos direitos da pessoa transexual. A autora aponta que memórias familiares de pessoas transexuais são quase sempre remetidas à dor e sofrimento, possivelmente resultados de episódios em que "pela promessa não cumprida, pelo desamparo, por não saberem o que iriam fazer delas mesmas, ou por não terem um repertório discursivo que lhes permitissem entender por que seus familiares as puniram com tanta violência” (BENTO, 2012, p. 280).

No que concerne à Mariana, destaca-se que sua expressão de gênero já condiz com a identidade social feminina: já utiliza roupas consideradas socioculturalmente como de mulher, faz uso de hormônios, maquia-se, pinta as unhas, usa calçados e utensílios como bolsas, colares e joias considerados femininos e já aplicou extensões capilares. Sua rede de apoio concentra-se em poucos/as amigos/as da Universidade, tendo uma convivência familiar conflituosa em função de sua condição sociossexual.

\section{A HORMONIZAÇÃO}

Mariana disse que fazia uso de hormônios há cerca de 4 anos. No início, começou por conta própria, mas hoje já faz acompanhamento médico pelo Instituto Nacional de Infectologia Evandro Chagas (INI) da Fundação Oswaldo Cruz (Fiocruz). Ela relatou como a adoção deste tratamento promoveu mudanças em suas atividades cotidianas:

M: Quando você inicia uma atividade você fica extremamente dolorida, com muitas dores musculares, essa é a marca que eu tenho, se eu fico um tempo sem fazer atividade, quando volto fico muito dolorida e muito cansada, e a diferença da força né, na força estática não sinto tanta diferença, mas as outras forças eu vejo que elas foram bem, não comprometidas, mas tiveram diferença significativa desde a utilização dos hormônios.

Em seu depoimento afirmou que, decorrente das mudanças físicas promovidas, seu rendimento no judô caiu: 
M: Como eu não competia no judô quando treinava aqui dentro [da UFRJ], sempre fui uma das pessoas mais fortes, e mesmo depois da transição continuei sempre forte, a diferença é que se viesse alguém aqui com meu nível, não só em questão de força, mas em adequação, que não é um nível competitivo, é muito diferente você treinar por hobbyou por objetivo, aqui [EEFD] sempre joguei todo mundo, não sentia diferença, e como não treinava em outro lugar não tenho resposta, mas o que eu sei é que meu corpo é totalmente diferente do que ele era antes, de maneira geral é tudo muito diferente.

Em pesquisa de Andrade (2017, p. 25), a autora constatou que o hormônio mais utilizado por mulheres transexuais é o estrógeno, através de suas formas "naturais (estrona, $17 \alpha$-estradiol e o $17 \beta$ - estradiol) ou os sintéticos (valerato de estradiol, benzoato de estradiol e etinilestradiol)”. A busca pelos hormônios ditos femininos faz parte da busca pelos atributos cisnormativos do corpo de mulher, tais como aumento das mamas, mudança do timbre de voz, diminuição de pelos pelo corpo e maior redistribuição de gordura corporal. Andrade (2017) destaca que a via de administração predominante é a oral, e função do seu baixo custo e pela facilidade de administração da substância. Também, esses hormônios podem ser combinados com o uso de antiandrógenos, tais como acetato de ciproterona.

Andrade (2017) também destaca que, em associação com progestegênios, substâncias que podem potencializador o desenvolvimento das mamas, aumentase o risco de efeitos adversos, principalmente "o risco de doenças coronarianas, acidente vascular cerebral e fenômenos tromboembólicos” (p. 25). Também, é comum ocorrer edemas nas extremidades corporais, retenção de líquidos, alterações no apetite, pouca disposição física, irritabilidade, enjoo, eventos tromboembólicos e alterações emocionais, tais como ansiedade e depressão, por exemplo.

Os riscos são variáveis de acordo com a dose administrada e se há acompanhamento médico ou não, sendo que ainda não são suficientemente documentados os efeitos adversos a longo prazo desse processo de hormonização cruzada. Porém, mulheres transexuais fazem uso desses elementos para além do aspecto fisiológico, já que aos hormônios é direcionada a concepção de correção do erro biológico, isto é, pela utilização dessas substâncias corrige-se aquilo que lhe foi suprimido ou que lhe falta para construir sua identificação. Mesmo tendo ciência dos riscos, os efeitos feminizantes se sobressaem no momento da tomada 
de decisão, tornando-se um processo de legitimação identitária para elas (ANDRADE, 2017).

\title{
O TRATAMENTO NA UNIVERSIDADE
}

Mariana descreveu como foi o processo de mudança de gênero, iniciado em 2015, e falou sobre a postura adotada por colegas e professores/as durante as aulas:

\begin{abstract}
M: Nesse momento eu já tinha passado nas disciplinas práticas, então nunca foi uma questão pros professores e turma, eu acho que as questões de gênero sempre foram as mais desmerecidas e que nunca foi pensado nesse período da graduação, e a única disciplina que isso refletiu alguma coisa foi na Prática de Ensino, que a professora estava muito preocupado em como me tratar, foi a única disciplina que teve um reflexo, ela sempre trabalhou mais incidente, e foi o lugar que isso ficou mais marcado, dentro da EEFD passa batido... e como eu já estou um tempo no corpo social da Universidade, as pessoas não pensam nessa questão.
\end{abstract}

O assunto não é diretamente tratado no curso, ainda que seja um espaço de formação de professores, onde seria extremamente pertinente debater sobre aspectos de gênero, sexualidade, raça e diferenças para auxiliar o próprio corpo docente e discente da unidade (CASTRO; BAPTISTA, 2019). Em pesquisa de Castro e Baptista (2019), os autores analisaram as ementas das disciplinas obrigatórias do curso de Licenciatura em Educação Física da EEFD/UFRJ para investigar como as temáticas de gênero e raça são abordadas em sua formação inicial. Como resultados encontraram que, das 68 ementas obrigatórias, apenas três abordavam aspectos raciais aplicados às práticas corporais e somente uma abordava efetivamente a temática de gênero.

Posto isto, o resultado da análise geral das ementas permite visualizar a escassez da discussão sobre o gênero nas diferentes práticas corporais, como também da questão racial em meio à cultura corporal vivenciada e discutida na sociedade atual. Não há nenhuma disciplina obrigatória cujo foco central seja a discussão de pelo menos uma dessas questões ao longo da formação do futuro professor de Educação Física (CASTRO; BAPTISTA, 2019, p. 6).

Em consonância, Garcia (2019) problematizou em sua dissertação de mestrado, à luz das relações de gênero e sexualidades, como a relação ensinoaprendizagem era estabelecida entre alunos/as-alunos/as e entre alunos/asprofessores/as de quatro disciplinas distintas da mesma unidade, encontrando 
resultados preocupantes sobre os desdobramentos das normas sociais durante a formação de professores/as de Educação Física: os alunos homens têm mais possibilidades de vivenciar os momentos práticos se comparados às mulheres; através de relações de poder, eles dominam os espaços das quadras e das atividades mais viris, enquanto que elas ocupam com maior destaque as atividades de ritmos e danças; as mulheres são objetificadas e sexualizadas pelos colegas de turma homens; os/as alunos/as, de forma geral, ridicularizam identificações de gênero o orientação sexual divergentes da heteronormatividade/heterossexualidade compulsória5, cometendo atos identificados como homofóbicos e/ou transfóbicos, e o corpo docente quase não se atenta para essas discussões, inclusive reforça essas desigualdades, com exceção de uma única professora de uma disciplina que aborda conteúdos históricos e culturais das práticas corporais.

Todavia, embora o quadro obrigatório de disciplinas não inclua uma quantidade de disciplinas significativa para problematizar as diferenças, há de se destacar a oferta de duas matérias optativas, sendo elas "Educação Física escolar e formação para diversidades" e "Gênero e Sexualidades na Educação Física e Esporte". Garcia et al. (2019) compartilham a experiência da turma de 2018.2 da segunda disciplina, debatendo sobre como a Educação Física continua sendo um espaço sexista e avesso às diferenças e abordando como se dá o reconhecimento da identidade de gênero e orientação sexual de homens e mulheres nas práticas corporais, dentre elas, a Dança e o Ballet Clássico. Essa produção é a síntese das discussões promovidas durante um bloco da disciplina, que é dividida em quatro módulos (GARCIA et al., 2019).

\footnotetext{
5 Brito (2018, p. 73-74) explica que o termo heteronormatividade "foi desenvolvido pelo estadunidense Michael Warner na introdução da obra Fear of a Queer Planet, no ano de 1991. Significa a normatização da ordem social por um conjunto de dispositivos, tais como discursos, valores e práticas, pelo pressuposto de que a heterossexualidade é o único modelo de orientação sexual possível, que busca controlar e regular a vida dos sujeitos, não apenas no que concerne à orientação sexual propriamente dita, como também na imposição de padrões de comportamentos atrelados ao binarismo de gênero". Brito (2018, p. 75) aponta também que "A noção de heterossexualidade compulsória, foi desenvolvida pela teórica feminista Adrienne Rich no clássico texto Compulsory Heterosexuality and Lesbian Existence. Rich buscou neste texto problematizar a invisibilidade lésbica nos textos acadêmicos ao colocar em discussão a heterossexualidade como uma instituição política, que retira compulsoriamente os direitos das mulheres, inclusive das mulheres heterossexuais, invisibilizando-as, assim como o processo de secundarização do movimento feminista num contexto de lutas políticas". Em linhas gerais, Franco (2018, p. 471) deduz que a partir dessas normas, “[...] criou-se um conjunto de dispositivos que se vinculam diretamente à produção de corpos, sujeitos e identidades definidos e coerentes com a sequência corpo/gênero/sexualidade”.
} 
Em meio a este cenário, Mariana destacou uma problemática ainda maior, que é a dificuldade que as instâncias sociais ainda apresentam de operar com as diferenças e fora do regime de ciscolonialismo:

M: A dificuldade é a forma de tratamento, a Universidade não está preparada para pessoas trans, ainda aquelas que têm alguma marca da testosterona. Não preciso usar sigla, mas uma pessoa que transita do masculino pro feminino, a universidade não consegue entender que existem mulheres com outras formas de corpo, e dentro da EEFD isso é muito complicado. Antes da retificação, ninguém podia resolver, falavam, olha não posso fazer nada, o que consta aqui é outro nome, aí você consegue resolver, mas a EEFD ainda é resistente a mudanças que nem são tão significativas.

Esse depoimento de Mariana evidencia a o combate da organização cisnormativa às diferenças enquanto relações sociais. Conforme explica Brah (2006, p. 363), sublinha-se "[...] a articulação historicamente variável de micro e macro regimes de poder, dentro dos quais modos de diferenciação tais como gênero, classe ou racismo são instituídos em termos de formações estruturadas". Em síntese, podemos compreender como a diferença enquanto relação social é “[...] entendida como as trajetórias históricas e contemporâneas das circunstâncias materiais e práticas culturais que produzem as condições para a construção das identidades" (BRAH, 2006, p. 363).

Essas conceituações, em termos práticos, traduzem-se em outros entraves, tais como a arquitetura e divisão dos banheiros e vestiários da unidade, por exemplo. Mariana explicou:

M: Um caso que eu já encontrei naquele banheiro ali perto do Brasil Brasilis [sala de aula do $2^{\circ}$ andar do prédio], quiseram dividir o banheiro em homem e mulher, a gente vê que a EEFD tá muito presa a esse corpo biológico, que o sexo anda com gênero, a maior dificuldade com EEFD é isso [...] Aqui, por exemplo [Universidade], não uso o banheiro, nenhum banheiro generificado, eu uso o que eles tentaram generificar dentro da EEFD, esse daqui de baixo, da Brasil Brasilis.

Em meio a essas dificuldades, Mariana relatou que durante toda a sua formação acadêmica, apenas uma professora se preocupou em dar atenção ao pronome com o qual a mesma gostaria de ser chamada: 
M: Foi só ela, como ela iria me tratar, se tinha alguma coisa que ia me incomodar... A única disciplina que a professora se preocupou, fez isso no primeiro dia de aula.

A presença de Mariana nas turmas poderia contribuir positivamente para as disciplinas tendo em vista as discussões sobre diferenças a partir dos gêneros, sexualidades e raças, mas quando questionada sobre seu impacto dentro do curso de Educação Física, ela afirmou:

M: Algumas disciplinas eu percebi que isso era bem marcado, e outras disciplinas não, dependia do professor... Fiz uma disciplina que o professor usou o pronome errado e eu nunca mais frequentei a disciplina, já numa outra a professora fez questão de saber meu nome, quem eu era, etc., desde o primeiro dia... Eu percebo a diferença de quem tá acomodando a turma dentro da disciplina, dentro dos espaços assim, sabe.

Essa desatenção do curso para receber e tratar as transgeneridades influencia diretamente na sua formação, deixando-a, em alguns momentos, desconfortável para complementar sua graduação - no momento da entrevista, Mariana disse estar no penúltimo semestre de sua formação, embora já tenha extrapolado o prazo mínimo recomendado. Quando questionada se o desconhecimento do trato com as diferenças a atrapalhou, ela respondeu:

M: Não, porque eu não estava preocupada com isso, mas atrapalhou no sentido de eu não querer concluir o bacharelado, por essas questões dessas disciplinas que faltam, serem professores extremamente transfóbicos.

Ao citar o bacharelado, perguntamos à Mariana se ela pensava em complementar sua formação, obtendo como resposta:

M: Já era uma coisa que seria uma complementação da minha formação, mas aí você encontra esse meio complicado e como você já tem uma graduação, você se pergunta: eu realmente preciso passar por isso? Eu acho que, ao mesmo tempo que é prejudicial, é uma atitude ruim, a gente pode resistir, mas uma denúncia formal não dá em nada, então é complicado... Só tem como resistir ou desistir quando você encontra esses professores extremamente resistentes.

E complementou:

M: A universidade ainda tá preocupado com sexo biológico e gênero, e pelo que a gente ainda tá no mundo, isso é uma grande 
preocupação... E a gente tá formando pessoas dentro de uma universidade e que vão encontrar pessoas diversas... eu estou passando incômodos, mas fora isso tenho minhas estratégias de sobrevivência né, que você acaba aprendendo a lidar com algumas coisas em determinados lugares.

Percebe-se nesta unidade o desenvolvimento de uma personalidade resiliente que enfrenta inúmeros obstáculos para ter o direito e acesso à educação, bem como ao reconhecimento civil de sua identificação pessoal. O desconhecimento e o preconceito face às diferenças continuam sendo os principais inimigos da formação de professores/as de Educação Física da EEFD/UFRJ, desencadeando, possivelmente, o que Garcia (2019, p. 92) já sinalizou: a reprodução, ainda que involuntária, de "[...] desigualdades de gênero, ocultas ou não, reforçando dessemelhanças fisiológicas e participações desiguais em exercícios para a Educação Física escolar”. Dos mais agravantes, o autor (p. 92) cita "[...] mecanismos homofóbicos, excludentes ou misóginos, por exemplo, já que esses processos foram reforçados veladamente na maior parte das ações durante a formação acadêmica”.

\section{A PARTICIPAÇÃO NOS JOGOS INTERPERÍODOS}

Anualmente na EEFD/UFRJ ocorrem os Jogos Interperíodos durante uma semana do calendário letivo, envolvendo as turmas da unidade nas principais modalidades esportivas ofertadas, tais como futsal, handebol, basquetebol, voleibol, natação, atletismo, entre outras. Mariana participou dos Jogos de 2015 e 2016, no início de sua transição, pelo naipe masculino, e nas edições de 2017 e 2018 disputou a competição pelo naipe feminino. Ela diz que nestas duas últimas ocasiões não enfrentou resistências das equipes, mas que após sua participação ficou sabendo da repercussão de seu caso:

M: Antes tinha aquela fala, mas não chegava ao meu ouvido. $\mathrm{Na}$ primeira edição [2017], só lembro de como eles iriam lidar com isso, eu não sabia, o dia que eu soube fui numa reunião e uma menina disse que não teria problema, mas que não sabia o que fazer... E depois fiquei sabendo que outra menina ficou falando que morria de medo de mim... E no de 2018 uma menina no banheiro falou que não queria lutar comigo porque eu era um homem que virou mulher, foram os únicos comentários que ouvi. [...]

E teve mais um caso de um menino, que disse que eu ia passar por cima das meninas e não sei que lá, só foram três que eu ouvi, na realidade um comentário, a percepção dela, eu vi que ao mesmo tempo que carregava preconceito, ela olhava pra mim e via uma 
pessoa extremamente forte, o medo dela foi pela força, não transfobia, mas tem transfobia porque ela não concebe o fato de ver uma mulher forte, e os outros casos me machucaram bastante, e foi a única coisa dentro do Interperíodos que eu vi. No segundo ano foi muito mais tranquilo que o primeiro, eu não estava nesses círculos de conversa, as pessoas podiam não me repassar, mas no segundo ano nem teve nada.

Para sua participação nos Jogos, Mariana teve apenas que se apresentar como mulher, não sendo-lhe exigido nenhum tipo de documento de identificação. Em reuniões promovidas pelos organizadores das duas edições, por votação, ficou definido que sua participação seria pelo naipe feminino.

Porém, como ela relata, o que se viu após a competição foi o desentendimento que existe entre o processo transexualizador e o reconhecimento da identificação da pessoa transexual. Neste, ainda é comum percebermos pessoas que não dissociam o histórico biológica do sujeito transexual de sua nova identificação, confundindo sua atual condição como uma transformação que seria, a qualquer momento, possível de ser facilmente desfeita - o que chega a ser uma falácia tentadora, já que está entranhado no pensamento coletivo social que "homens biológicos se tornariam" mulheres transexuais para obterem melhores desempenhos esportivos, como destacam Castro, Garcia e Pereira (2020).

Também, a maneira como o Esporte permanece se (re)estruturando na pós-modernidade corrobora para a desistência de todo e qualquer corpo que não apresente os índices identificadores de cada modalidade (MACHADO, 2019). Apresentar-se transexual é ainda mais perturbador para este fenômeno, já que ele se estrutura sobre uma matriz cissexista que sequer consegue compreender a transgeneridade, estimulando dúvidas de onde realocar a pessoa trans - isso se ela puder ser realocada, já que é mais fácil e menos emblemático silenciar essa identificação e exclui-la do Esporte.

6 Sentença entre aspas por ser um entendimento acrítico do senso comum, uma vez que ninguém nasce homem; que a biologia é uma ciência produto de um discurso cisnormatizador e; que o processo de "tornar-se" alguma categoria de identificação é opcional ao longo da vida de qualquer sujeito (PRECIADO, 2019). 


\title{
DIFERENÇAS MARCANTES ENTRE O VOLEIBOL E O JUDÔ
}

Mariana contou que sua inserção no Esporte se deu por meio do voleibol e que por muito tempo conciliou essa prática esportiva com o judô. Ela destacou as principais diferenças que pôde perceber entre essas duas modalidades:

\begin{abstract}
M: O judô tem uma filosofia, né... a sexualidade é o que menos importa pra maioria das pessoas ali dentro [...] no judô isso não é importante, já no voleibol isso é bem mais marcado, as pessoas têm mais incômodo, mas no judô ok, LGBT não interessa, interessa o resultado.
\end{abstract}

Nas competições que participou durante sua identificação como homem homossexual, ela afirmou que:

M: Sempre teve respeito [no judô], na torcida ninguém falava 'ah ô viado', como já aconteceu no vôlei, no judô não, as pessoas vão ver o espetáculo e ponto final.

Para Mariana, no voleibol as diferenças de gênero e sexualidades são mais notórias, diferentemente do judô. Nesta seara, é pertinente destacar aqui o imaginário social que se constrói sobre as duas modalidades. O judô é considerado um esporte de combate e, historicamente, nunca registrou oficialmente a participação de um/a atleta transexual pelos dojôs (inter)nacionais. $\mathrm{O}$ caso que mais se aproxima desse evento, mas que não o configura, é o da brasileira Edinanci Silva ${ }^{7}$, judoca que na década de 1990 quase foi impedida de atuar profissionalmente por apresentar características ditas de intersexo. A atleta teve de se submeter a procedimentos cirúrgicos para retirada de testículos internos, onde só então foi autorizada a atuar.

O caso de Edinanci muito repercutiu na época, pois sua aparência física (corpo musculoso e delineado, e cabelos curtos) era dissociada da representação social de feminilidade, o que inclusive levantou suspeitas sobre seu verdadeiro sexo biológico, mesmo a atleta tendo se desenvolvido, majoritariamente, como do sexo feminino. Também, são poucos os relatos de judocas que se autodeclaram como não heterossexuais. $\mathrm{O}$ caso mais recente, também brasileiro, é o da judoca negra Rafaela Silva, abertamente declarada lésbica, que conquistou a medalha de ouro nos Jogos Olímpicos do Rio-2016, sendo ovacionada pelo ginásio. A mesma Rafaela que, após ser desclassificada nos Jogos de Londres de

7 Cf. "Além de Tifanny, outros casos de diversidade de gênero no esporte". https://veja.abril.com.br/esporte/alem-de-tifanny-outros-casos-de-diversidade-de-genero-no-esporte/ 
2012 por ter cometido um golpe considerado ilegal, foi chamada de "macaca" e "sapatão" por internautas brasileiros em redes sociais virtuais". Em suma, esse episódio ilustra o caráter ciscolonialista que está encrostado no universo esportivo, avesso às diferenças étnico-raciais e/ou sociossexuais.

Já o voleibol é uma modalidade à parte no universo esportivo. Diversos/as autores/as já problematizaram o terreno fértil do mesmo para as manifestações das corporalidades que desviam das cisheteronormativas (BRITO, 2016; 2017; 2018; 2019). O autor expõe que, historicamente, a modalidade se consolidou como antagonista direta do "futebol dos machos", sendo muito mais permissível para as mulheres e homossexuais. Diferentemente do judô, casos de atletas não heterossexuais não faltam pelo voleibol, tais como o de Lilico, Michael Santos, Vinicius Santos, Douglas Souza, Isabelle Neres e Tifanny Abreu (BRITO, 2018).

Mariana, em sua atuação pelo voleibol universitário, chegou a representar a equipe masculina da UFRJ nos III Jogos do Vale Paraíba realizado em 2014 na cidade de Lorena/SP. Na ocasião, a UFRJ conquistou o ouro na competição, com participação nas quadras de Mariana.

Em 2015, quando iniciou sua transição, Mariana continuou participando dos treinos da equipe representativa tanto masculina quanto feminina, porém apenas para composição. O principal fator que motivou essa decisão foi o fato de não poder atuar por onde gostaria, entre as mulheres. Posteriormente, em 2018, ausentou-se dos treinos e desistiu do voleibol.

Cabe destacar aqui que, em pesquisa bibliográfica, não encontramos sequer um resultado que abordasse a temática de estudantes/atletas transexuais no esporte universitário, sendo essa uma área promissora para a realização de estudos sobre a temática em tela. Recomendamos que também seja alvo de investigação a maneira como a Confederação Brasileira de Desportos Universitários (CBDU) lida com a situação, uma vez que o número de estudantes transexuais em universidades brasileiras vem crescendo ano após ano, fruto de programas de assistência estudantil (MESQUITA; RODRIGUES, 2019).

8 Cf. "Rafaela Silva: ‘O ginásio tremeu. As adversárias sentiram a pressão”. Rafaela Silva: "O ginásio tremeu. As adversárias sentiram a pressão" - ÉPOCA | Olimpíadas (globo.com)

9 Na Educação Física, os trabalhos que problematizam as manifestações dissonantes das cisheteronormativas no Esporte encontram-se em ascensão desde meados da década de 2010, através de autores como Wagner Camargo, Silvana Goellner, Luiza dos Anjos, Angelita Jaeger, Fabiano Devide, Leandro Brito, Allyson Araújo, Bárbara Pires, Thiago Iwamoto, Ludmila Mourão, Vagner Prado e Erik Pereira. 
Portanto, estudantes/atletas transexuais em competições universitárias já é mais uma realidade que necessita ser problematizada, tendo em vista que alguns desses programas de assistências estudantil, tais como o PNAES, por exemplo, garante, entre outros, o direito de participação em atividades esportivas junto à instituição de ensino superior ao qual o/a aluno/a encontra-se regularmente matriculado/a (MESQUITA; RODRIGUES, 2019).

\section{PERSPECTIVAS PARA O ESPORTE E VIDA PROFISSIONAL} atuação:

$\mathrm{Na}$ área da Educação Física, Mariana não vê grandes possibilidades de

M: É um mercado que não tá preparado para esse tipo de atuação, no mercado é tudo escasso... Na realidade, nenhum mercado tá preparado para pessoas transexuais. Toda vez tem que explicar a história que eu tenho de vida pra procurar emprego [...] Mas você vê que as pessoas não sabem e não estão preocupadas com essas coisas, se preocupam com coisas menos importantes da nossa formação. A educação física precisa mudar bastante, na educação física só encontra homens trans, que tem a passabilidade cis, alguns dizem outros não, é diferente de mulher trans, não conheço nenhuma que seja professora.

No seu caso, disse que não se considera “passável”, isto é, socialmente as demais pessoas conseguem perceber sua condição transexualizada, muito por conta do timbre de sua voz. Esse é um dos principais entraves que geram esse afastamento por parte de Mariana:

M: É mais fácil buscar outra coisa pra te dar resultado, é o que acontece, pelo menos comigo. Não sei de outras pessoas trans, de outras áreas, o que acontece, mas na educação física vejo um afastamento, até em entrevista, você chega pra ser humilhada... A minha estratégia é ou você resiste ou você desiste, eu prefiro desistir, porque eu to encontrando outras coisas fora da educação física, então pra eu não ter esse desgaste... Eu sempre repenso, eu gosto muito de judô, e aí teve até um menino que comentou 'vamos pegar faixa preta', porque pra trabalhar com isso tem que ser faixa preta, mas aí você vai enfrentar resistência porque é transexual, então tem que pensar e repensar toda vez isso. Pra educação física eu não tenho expectativa nenhuma, nem de trabalho, eu acho que é uma coisa que não vai rolar. É um arrependimento de estar na profissão que não tá preparada e eu sabia que não ia acontecer. 
Quando perguntamos sobre sua pretensão de continuar competindo nas modalidades em que atuava, Mariana disse:

M: Na realidade eu queria, só que a gente tem vários empecilhos enquanto pessoa trans. A minha maior dificuldade é sempre essa, por exemplo, no judô, eu estou passando esse ano todo [2019], não consegui encontrar uma menina que eu queria fazer o treino num lugar que me acolhesse enquanto competidora trans, tá sendo muito difícil... E como o judô é o esporte que eu já tenho maior prática, seria mais fácil, e a adaptação seria muito mais fácil do que pra um esporte novo.

[...]

Dentro da federação [de judô] não tem nada, nos documentos oficiais não tem nada, então não tem nenhuma menção a pessoas trans, aí eu ia voltar a competir, mas tem isso né, e as regras, você fica nessa, não sou tão nova pra construir uma carreira como atleta, pra mim é perda de tempo, ficar demandando esse tempo, o que eu penso é fazer um estudo de caso da inserção de uma pessoas transgênero que já foi federada e uma federação que não tá preocupada com isso.

[...]

Pra você estar inserida num esporte você tem que ter apoio desse esporte, quando ele é do alto rendimento você tem que ter mais um apoio, e como você vai entrar numa parada que você tem que construir alguma coisa se você não sabe o resultado final e se vale a pena? Vale a pena ser atleta numa modalidade que não tá preparada? A nível estadual ela não tá preparada... O judô é muito conhecido nacionalmente, mas no Rio só tem três clubes de alto rendimento no sentido de ter muita gente pra treinar, um na Taquara, outro na Gávea e outro na Ilha, e nem sei se tá funcionando ainda, então tem dois grandes polos, o resto é um atleta ou outro que ascende, e quando você quer treinar e tem dinheiro você vai onde tem mais possibilidades, vai te oferecer viagens, o que num lugar menos você teria que arcar com essas despesas, e quando você tá numa idade avançada isso já não é tão jogo, porque o judô não é como o voleibol, pra jogar em liga estrangeira, ou o handebol, que meninas trans também tão jogando, mas no voleibol tem mais, e no judô você tem menos... As pessoas trans não são tão inseridas no esporte, e a gente não tem tantas pessoas trans no mundo.

Como destacado por Mariana, a Educação Física ainda é uma área que apresenta fortes resistências às identificações trans de modo geral, sendo este um possível reflexo do regime de ciscolonialismo que se esvai por essa esfera do conhecimento. De fato, se fizermos um exercício de reflexão, quantos/as professores/as de Educação Física são transexuais e estão atuando regularmente 
em escolas e/ou espaços de treinamento, como clubes, academias e o Esporte de alto rendimento? Franco (2016) discorre sobre as dificuldades que esse público enfrenta no espaço escolar, enfrentando resistências tanto do corpo discente como de seus pares docentes, não sendo algo exclusivo da Educação Física, mas sim de toda a instância educativa de forma geral (FRANCO, 2018).

Neste sentido irrompe a transfobia ${ }^{10}$, um mecanismo de defesa acionado para proteger a cisheteronormatividade, o que muitas vezes resulta na não contratação da pessoa trans, no distanciamento da mesma dessas práticas profissionais e corrobora para cada vez mais marginalizar este público que, se comparado aos demais grupos sociais, é um dos mais vulneráveis às situações de vida precária (FRANCO, 2018). Conforme explica o autor,

O fenômeno da transfobia pode ser definido como um processo
de recusa histórica, social e cultural pela forma como travestis,
transexuais e transgêneros constroem seu gênero e vivem suas
sexualidades. O aspecto mais marcante seriam as diversas
dimensões de vulnerabilidade a que esses sujeitos são expostos em
razão de se constituírem como o/a outro/a do gênero e das
sexualidades, portanto, o/a outro/a na condição de direitos
humanos (FRANCO, 2018, p. 476).

Atentos aos demais marcadores da diferença cabe destacar que, para além de mulher transexual, Mariana também é negra, de baixa classe social e periférica. Em suma, tudo aquilo que o ciscolonialismo abomina e tenta converter moral e eugenicamente. Talvez por tais marcadores é que sua presença incomode tanto pelas salas de aula que adentra, nos mercados formais que procura, pelas quadras em que joga e, possivelmente, pelos tatames em que luta. Resta-lhe apenas a opção de lutar e resistir contra esse cistema que, entretanto, já a venceu ao fazêla desistir do judô, do voleibol e da própria profissão.

Conforme sinaliza Machado (2019), a desistência esportiva de pessoas trans ocorre em função do não reconhecimento social das identificações trans (de onde pode irromper a transfobia), da falta de incentivos para inserção e manutenção deste público no Esporte e dos resultados promovidos pelo conjunto genético, fisiológico e pelo meio social às pessoas trans. Assim, os processos de legitimação esportiva, de pertença, de (des)vantagens e condições desiguais entre os corpos que se aventuram às práticas esportivas acaba por beneficiar as pessoas cis nesta

10 Vergueiro (2015) sugere uma compreensão decolonial para o fenômeno de transfobia, entendendo-a como resultado da institucionalização sociocultural dos regimes violentos de cisnormatividade e cissexismo tão enraizados nas sociedades ocidentais. 
extensão da prática corporal humana, sendo mais uma engrenagem ciscolonialista para (re)produzir corpos cistêmicos na sociedade pós-moderna.

\section{CONSIDERAÇÕES FINAIS}

Neste trabalho, entrevistamos Mariana Carvalho dos Santos, uma atleta/estudante da EEFD/UFRJ, mulher transexual, negra, periférica e de baixa renda. Perguntamos sobre a participação dela nas modalidades esportivas que praticava na época, o judô e voleibol, levantando seu histórico nessas modalidades, e também foi de nosso interesse compreender as relações sociais estabelecidas pela/na instituição acadêmica em questão.

Os principais resultados apontaram que Mariana enfrentou resistências internas e externas às instituições esportiva e acadêmica, tendo que lidar com processos transfóbicos à luz da cisheteronormatividade e ciscolonialismo, bem como a denegação por parte de membros de seu entorno social. Constantemente coagida pelas normas cistêmicas, Mariana não conseguiu desenvolver sua carreira nas modalidades que almejava, perdendo a melhor fase, segundo ela, para tornarse de fato profissional.

As dificuldades enfrentadas por Mariana, tais como sua não passabilidade de gênero, os efeitos adversos da hormonização, o não reconhecimento de sua identificação homossexual e, posteriormente, transexual, bem como os trâmites burocráticos do Estado, do próprio corpo discente e docente da Universidade e do mercado de trabalho da Educação Física fizeram com que a mesma se desiludisse com a profissão na qual está se graduando, inclusive motivou-a a desistir de fazer a complementação da mesma.

Em suma, este trabalho evidenciou estratégias sutis e outras mais desveladas do ciscolonialismo e da cisheteronormatividade que moldam a cultura social e popular ao qual Mariana está inserida, onde os marcadores que formulam sua própria identificação são constantemente repelidos pelos demais membros sociais, resultando em um processo conflituoso de subsistência, que instiga Mariana a ter que pensar em novas e múltiplas formas de poder continuar (r)existindo e sobre(vivendo) na metrópole do Rio de Janeiro.

\section{REFERÊNCIAS}

ANDRADE, Carla Andreia Alves de. Autocuidado de mulheres transexuais em uso de hormônios à luz da Teoria de Orem. 2017. 107f. Dissertação (Mestrado 
em Enfermagem). Programa de Pós-Graduação em Enfermagem, Universidade Federal de Pernambuco, Recife/PE, 2017.

BENTO, Berenice. As famílias que habitam "a família”. Sociedade e Cultura, Goiânia, v. 15, n. 2, p. 275-283, jul./dez. 2012.

BRAH, Avtar. Diferença, diversidade, diferenciação. Cadernos Pagu, Campinas, n. 26, p. 329-376, jan./jun. 2006.

BRITO, Leandro Teófilo de. "Deixa a pinta pra fora da quadra": sobre heteronormatividade e precariedade no contexto do voleibol. In: SEMINÁRIO INTERNACIONAL ENLAÇANDO SEXUALIDADES, 1. 2017, Salvador/BA. Anais... Salvador/BA, 2017. Disponível em: < https://www.editorarealize.com.br/revistas/enlacando/trabalhos/TRABALHO_ EV072_MD1_SA18_ID268_19062017192331.pdf >. Acesso em 27 mar. 2020.

BRITO, Leandro Teófilo de. Enunciações de masculinidade em narrativas de jovens atletas de voleibol: leituras em horizonte queer. 225p. Doutorado (Programa de Pós-Graduação em Educação) - Faculdade de Educação da Universidade do Estado do Rio de Janeiro, Rio de Janeiro, RJ, Brasil.

BRITO, Leandro Teófilo de. Identificações performativas do masculino no voleibol: narrativas de jovens adolescentes atletas em debate. Esporte e Sociedade, Niterói, v. 11, n. 28, p. 1-20, set. 2016.

BRITO, Leandro Teófilo de. Performances dissidentes no espaço do voleibol: masculinidades queer? In: PEREIRA, Erik Giuseppe Barbosa; SILVA, Alan Camargo (Orgs.). Educação Física, Esporte e Queer: Sexualidades em Movimento. Curitiba: Appris, 2019. p. 83-103.

CASTRO, Pedro Henrique Zubcich Caiado de; BAPTISTA, Guilherme Gonçalves. Gênero, raça e formação docente: análise das ementas da Escola de Educação Física e Desportos-UFRJ. Educación Física y Deporte, Medellín, v. 38, n. 2, p. 1-10, jul./dez. 2019.

CASTRO, Pedro Henrique Zubcich Caiado de; GARCIA, Rafael Marques; PEREIRA, Erik Giuseppe Barbosa. O voleibol e a participação de atletas trans: outro ponto de vista. Motrivivência, Florianópolis, v. 32, n. 61, p. 01-22, abr. 2020 . 
FRANCO, Neil. A Educação Física como território de demarcação dos gêneros possíveis: vivências escolares de pessoas travestis, transexuais e transgêneros. Motrivivência, Florianópolis, v. 28, n. 47, p. 47-66, mai. 2016.

FRANCO, Neil. Transfobia e cotidiano escolar: impactos na relação docente/discente. Revista de Educação Pública, Cuiabá, v. 27, n. 65/1, p. 469486, mai./ago. 2018.

GARCIA, Rafael Marques et al. Educação Física escolar, a Dança e o Ballet clássico: possíveis interlocuções à luz das relações de gênero. Arquivos em Movimento, Rio de Janeiro, v. 15, n. 2, p. 38-55, jul./dez. 2019.

GARCIA, Rafael Marques. Desdobramentos da heteronormatividade na formação de professores de Educação Física em uma universidade pública do Rio de Janeiro. 2019. 225f. Dissertação (Mestrado em Educação Física) - Escola de Educação Física e Desportos, Universidade Federal do Rio de Janeiro, Rio de Janeiro/RJ, 2019.

GOELLNER, Silvana Vilodre. "As mulheres fortes são aquelas que fazem uma raça forte”: esporte, eugenia e nacionalismo no Brasil no início do século XX. Recorde: Revista de História do Esporte, Rio de Janeiro, v. 1, n. 1, p. 1-28, jun. 2008.

MACHADO, Anna Cristina Alvares Ribeiro. Alguns apontamentos sobre a diversidade de gênero nos esportes. RECITAL - Revista de Educação, Ciência e Tecnologia de Almenara, Almenara, v. 1, n. 2, p. 37-60, set./dez. 2019.

MESQUITA, Camila Nogueira Chaves; RODRIGUES, Samantha Guedes Clemente. Estudo exploratório sobre a temática da transexualidade no ambiente universitário: reflexões e a intervenção do serviço social. In: $16^{\circ}$ Congresso Brasileiro de Assistentes Sociais: "40 anos da "Virada" do Serviço Social", Brasília/DF, Brasil, 2019. Anais... Disponível em: < http://broseguini.bonino.com.br/ojs/index.php/CBAS/article/view/638/622 >. Acesso em 20 jan. 2020.

PRECIADO, Paul Beatriz. Un appartement sur Uranus: Préface de Virginie Despentes. Paris: Grasset, 2019. 
RIBEIRO, Djamila. Mulheres e Esporte. In: Movimento é vida: atividades físicas e esportivas para todas as pessoas. Relatório Nacional de Desenvolvimento Humano do Brasil. PNUD: Brasília/DF, p. 1-12, 2017.

SOARES, Milene et al. $\mathrm{O}$ apoio da rede social a transexuais femininas. Paidéia, Ribeirão Preto, v. 21, n. 48, p. 83-92, jan./abr. 2011.

STAKE, Robert E. Investigación con estudio de casos. 2 ed. Madrid, Ediciones Morata, 1998.

VERGUEIRO, Viviane (Simakawa). Por inflexões decoloniais de corpos e identidades de gênero inconformes: uma análise autoetnográfica da cisgeneridade como normatividade. 2015. 243f. Dissertação (Mestrado em Cultura e Sociedade). Instituto de Humanidades, Artes e Ciências Professor Milton Santos, Universidade Federal da Bahia, Salvador/BA, 2015.

Recebido em 18 de maio de 2020

Aprovado em 16 julho de 2020 